\title{
VB.NET Programming Course Teaching Based on Computational Thinking
}

\author{
Xu Ling ${ }^{1}$, He Wei ${ }^{2}$ \\ ${ }^{1}$ College of Computer Science, Sichuan Normal University, Chengdu, China \\ ${ }^{2}$ College of Information Technology, Sichuan Normal University, Chengdu, China \\ xlyeah@yeah.net, hovey126@126.com
}

\begin{abstract}
Computational thinking training is the core task of computer foundation courses, according to the computational thinking concept and meaning, in view of the problems existing in the VB.NET programming course teaching, combed the main computational thinking involved in VB.NET programming course, and puts forward the corresponding training methods.

Index Terms - Computational thinking. VB.NET. Teaching.

\section{Introduction}

Since the expound systematically of Computational thinking by Professor Jeannette M in 2006, the concept of Computational thinking obtained great attention [1], many scholars have made a lot of discussions on the nature and significance of computational thinking [2-4]. And has sparked re-examine and discuss about computer foundation course teaching content and teaching goals among computer scholars, in July of 2010, the first "nine school alliance (C9) computer basic course seminar" established the core task of computer basic education is cultivating computational thinking [5-6]. In recent years, some of computer educators have conducted the research and the practice of computational thinking training in computer basic course [7-9], but the discussion on VB.NET curriculum in computational thinking training is also less involved. According to the VB.NET curriculum characteristics, combing the computational thinking in VB.NET, and pay attention to cultivating computational thinking in teaching, have gained some experience.
\end{abstract}

\section{Computational Thinking}

Computational thinking is put forward by professor Jeannette $\mathrm{M}$ at the department of computer science of Carnegie Mellon University in USA at 2006, she has given the definition as: Computational thinking is to solve problem and design system using the basic concepts of computer science, is a series of thinking activity about human behavior understanding which covers of the breadth of computer science [10].

Professor Jeannette M explain of computational thinking further as: Computational thinking is state a seemingly difficult problem to one we know how to solution through reduction, embedding, transformation and simulation method; computational thinking is a kind of recursive thinking, is a kind of parallel processing, is a kind of translate code into data and translate data into code, a type of checking method of multidimensional analysis; computational thinking is a kind of method using abstraction and decomposition to control complex tasks or for large complex system design, it is of concern separation method; computational thinking is a thinking method of select suitable way to present a problem, or modeling on a problem with the relevant aspects to make it easy to handle; computational thinking is a thinking of prevention, protection and restoration in the worst case through redundancy, blocking fault, error correction method; computational thinking is a thinking method to search for answers using of heuristic reasoning, that is planning, learning and scheduling in cases of uncertainty, is thinking method to speed up the calculation using the massive data, to compromise between time and space, between the processing power and storage capacity.

At present, computational thinking tied with experimental thinking and theoretical thinking are considered the three scientific thinking way of human [4]. Computational thinking represents a common understanding and a kind of universal skills, is everyone's basic skills, not just belong to the computer scientists. Therefore, in the teaching of computer course, should pay attention to cultivating students' computational thinking.

\section{Computational Thinking in the Course of VB.NET Programming}

VB.NET is one of the programming languages in the .NET frame of Microsoft Corp, is a visual programming language, and has the features of object oriented, is selected language in programming courses at many colleges and universities. As the programming courses, there is a lot of computational thinking in it. However, traditional teaching methods often focus on grammar and its simple application, although also will talk about some algorithms, but are often confined to the algorithm itself, not to the level of teaching thinking method. That causes the student impression of this course with boring and difficult to learn, not practical. Therefore, we according to Professor Jeannette $\mathrm{M}$ on definitions and interpretation of the computational thinking, combined with discussions among computer teaching experts on Computational thinking [1-6], according to the VB.NET course characteristics, to tease out the computational thinking contained in VB.NET, as shown in Table I, and make cultivating computational thinking as the goal of the course, effectively improve the students' thinking ability and programming ability. 
TABLE I Main Computational thinking in VB.NET Course

\begin{tabular}{|l|l|}
\hline \multicolumn{1}{|c|}{ knowledge point } & \multicolumn{1}{c|}{ correspond computational thinking } \\
\hline $\begin{array}{l}\text { Data types, constants } \\
\text { and variables }\end{array}$ & Data representation problem \\
\hline Branch, loop structure & Enumeration, iteration, recursion method \\
\hline multithreading & parallel processing \\
\hline drawing & object oriented programming \\
\hline $\begin{array}{l}\text { File and database } \\
\text { operations }\end{array}$ & Data storage, Separate data from program \\
\hline Exception handling & System error correction, protection and restoration \\
\hline Integrated project & $\begin{array}{l}\text { comprehensive application of the Computational } \\
\text { thinking, program evaluation }\end{array}$ \\
\hline
\end{tabular}

Data types, constants and variables involves binary numbers and their operations, fixed-point and floating-point concepts, but here, the focus is not operational and the concept itself, but rather why the computer use binary number, why there are fixed-point and floating-point numbers, what is the meaning and the benefits they bring. So to explain the representation of data in computer and resource constraint problem when solve problems.

Branch and loop structure is the basic structure of the computer program, understanding and apply of these two kinds of program structure is the basic skills necessary to write program. In traditional teaching, the key teaching points is the execution process of the two kinds of structure. But if starting from cultivating computational thinking point of view, should be through the typical case selection, analysis methods of problem solving such as enumeration, iteration, recursion, etc. Promote students' study from understanding the statements to methods of solving problems. Learn analysis, solve problem based on the features of computer.

The concept of multi-thread is a kind of ideas of parallel processing, is one of the means to improve the running efficiency of program and to solve complex problems. The idea of parallel processing is common in life, so students are easy to understand, but in program, must considering "resource sharing" problem when use of multithreading, that is the thread synchronization.

In the VB.NET, drawing become a very easy thing, because the system has been preset many drawing related classes, the drawing process is the process of using various drawing objects, like the manual drawing process. This is the very good content to help student understanding object-oriented programming.

File and database operations, related to the storage and management of data in computer problem, which involves the separation of concerns programming ideas.

Structured error handling mechanism of VB.NET, including structured programming idea, involves "decomposition" and "concision" programming idea.

Through the design of integrated project, variety of computational thinking can be comprehensive utilized. At the same time, the design and development process of the integrated projects, will apply a very important method in computer programming: top-down, stepwise refinement, which is consistent with the idea of "simplify complex problem" in life. Design and development of integrated projects, can cultivate students' learning "to solve the problem, design system with the fundamental concepts of computer science, and understand human behavior".

\section{Computational Thinking Training in VB.NET Programming Course}

In order to training students' computational thinking in the course, we should pay attention to the following aspects:

The basic concept is the fundamental, is the basis for learning other content, but in terms of the basic concept, not only confined to the concept itself, but to extend, linked to the actual life of students, make the concept concrete and visualized. For example, Process is one of the difficulties in learning VB.NET, in order to make the students understand the concept and learn to use, use the following analogy: a program such as a class held an activity, a process as a dance team of a class, dance team has dance ability (process has relatively independent function), when the dance is need in activity, invite dance team performances (call process), but should be explained the dance style and time information and so on, so that the dance team prepare (parameters transfer). Moreover, the Object is a teaching difficult point, in order to explain what is Object, the CD player as an example, the CD player has some attributes(Object has attributes, too), such as color, thickness; also has some functions (operations), such as play, pause, forward and backward, etc. When we need to play music, to press the play button (message transfer), CD players will play music (receive message and response).

Courses focus on thinking, methods, how to abstract the problems, and find out the formal method to solve the problem, and then write the program. Let the students learning method through cases, but not take the matter on its merits, only in order to solve the case as the purpose. There is often such a phenomenon, students familiar with complex keyword, statement, function, can read program, but when it comes to write a program, do not know how to start. Cannot solve practical problems use the learned knowledge. Investigate its reason, is mainly because the students do not know how to abstract and symbolic the practical problems, do not know how to analyze and solve problems according to computer features. Therefore, in the process of analyzing and solving the case teaching, should pay attention to summarize methods, let the students learning the ways of solving problem, to facilitate transfer of learning.

The cases should be life of, close to the student life, enable students to understand the meaning and usage of knowledge, rather than learn for the sake of learning, learn for exams. At the same time, in teaching process, should also pay attention to the step-by-step teaching, from the shallower to the deeper. For example, in terms of circulation structure, first classic example is add numbers from 1 to 100, to specify the use occasions and necessity of cycle, and loop execution process; then, the second example is one hundred Yuan to buy a hundred chickens, to illustrate the nesting cycle; finally, the case analysis as an example, combining circular and logic, at the same time, also relates to the application of the 
enumeration method. Students are very interested in the very strong comprehensive and practical cases, once solved, will feel a sense of achievement, and can increase the interest in courses.

Comprehensively use of different teaching methods according to different teaching contents and teaching goal. For example, in terms of basic concept, mainly using lecture method, can reduce the learning time, increase the accuracy of students to understand the concept ; in the process of lecture method, can be combined with problem-based teaching method, promotes the students' understanding and distinguish the relations between concepts; for strong logic problem, adopt group discussion, through discussion between team members, promote students' thinking training and form; major task of each chapter or at the end of the term, adopt task driven method, let the students comprehensive application of the learned content in the process of solving the task. For example, when teaching multithreading, to elicit the concept of multi-thread, give a task as: Simulation of three people drawing flower in a piece of canvas and respectively at different speed. Let the students discuss solution in groups. The difficulty of this task is that the three petals to draw in the same time but in indifferent speed. Through group discussion, students often can give some solutions, such as to draw petal one by one through recirculation, each petal draw apart every time by using the Timer control, etc. Then, teachers and students work together to analyze the shortage of each method, which leads to the concept of multi-thread, thus students can understand the concept of multi-thread deeply; then, with the depth of the problem, elicit the thread synchronization problem. Thus, combination questions and discussion, is a very good training process of students' thinking.

\section{Conclusions}

The core task of computer basic course is to train the students' computational thinking. To develop computational thinking of students, teachers should first have computational thinking consciousness, with the computational thinking consciousness, teachers will select targeted cases, and use of appropriate teaching methods, promote the training of the students' thinking and culture, to achieve the purpose of computational thinking cultivating. The programming course teaching aim at computational thinking training, the cases are practical and interesting, avoid the boring of grammar and the sentence study in the traditional teaching mode, will increase the students' interesting in learning, training students the computational thinking. There are many computational thinking in computer courses, "almost every concept corresponds to a computational thinking method" [1], therefore, one course cannot cover all the Computational thinking. But once possess the computational thinking consciousness, computational thinking is everywhere, will eventually become everyone's thinking skills.

\section{References}

[1] P.Z. Gong, "Computational thinking training in University Computer Foundation Teaching," China University Teaching,no.5, pp.51-54, 2012

[2] R.S. Dong, "Computational thinking and Methodology of Computer Science and Technology," Computer Science, vol.36, no.1, pp.1-4, 2009.

[3] R.S. Dong, "Computational thinking and Introduction to Computer Science," Computer Science, vol.36, no.4, pp.50-52, 2009.

[4] Y.Z. Zhu, "Computational thinking: its Scientific Position, Basic Principles and Innovation Methods," Computer Science, vol.36, no.4, pp.53-55, 2009.

[5] Q.M. He, H.Q. Lu, B.Q. Feng, "The core task of computer basic teaching is cultivating Computational thinking Ability," China University Teaching, no.9, pp.5-9, 2010.

[6] R.S. Dong, "Nine school alliance (C9) strategy for the development of basic computer teaching joint declaration calls for the transformation of Education," China University Teaching, no.10, pp.14-15,2010.

[7] P.J. Huang, D.F. Xu, J.J. Yin, "Computational thinking Cultivating on experimental teaching of principle of Computer Organization," Computer Education, no.16, pp.103-106, 2012.

[8] W.J. Wang, J.S. Deng, J. Wang, "A Teaching Mode Research of Database Series Curriculum System Based on Computational thinking," Journal of Linyi University, vol.34, no.6, pp.66-69, 2012.

[9] X.Q. He, J.H. He, "Computational thinking Cultivating on the course of computer introduction," computer Education, no.15, pp.69-72, 2012.

[10]M. Jeannette, "Computational thinking," Communications of the ACM, vol.49, no.3, pp.33-35, 2007. 